\title{
A Meta-Analysis of Plasma Homocysteine in Buerger's Disease
}

\author{
Mira Merashli ${ }^{1}$ Tommaso Bucci ${ }^{2}$ Daniele Pastori ${ }^{3}$ Pasquale Pignatelli ${ }^{3} \quad$ Alessia Arcaro $^{4}$ \\ Fabrizio Gentile ${ }^{4}$ Vincenzo Marottoli ${ }^{5}$ Paul R.J. Ames (6,70 $^{6}$
}

${ }^{1}$ Department of Rheumatology, American University of Beirut, Beirut, Lebanon

2 Department of General Surgery, Surgical Specialties and Organ Transplantation "Paride Stefanini," Sapienza University of Rome, Rome, Italy

3 Prima Clinica Medica, Atherothrombosis Centre, Department of Clinical, Internal Medicine, Anaesthesiologic, \& Cardiovascular Sciences, Sapienza University of Rome, Rome, Italy

${ }^{4}$ Department of Medicine \& Health Sciences 'V.Tiberio', University of Molise, Campobasso, Italy

${ }^{5}$ Multimedica SRL, Naples, Italy

6 Immune Response and Vascular Disease Unit, CEDOC, Nova University Lisbon, Lisbon, Portugal

7 Department of Haematology, Dumfries Royal Infirmary, Dumfries, United Kingdom

Thromb Haemost 2022;122:1243-1246.

Buerger's disease (BD) is a vascular inflammatory disease that commonly affects all three layers of small and medium arteries of upper and lower extremities in a progressive and segmental fashion; characteristically, BD develops in males, mostly smokers, within the 20 to 50 years age range. Claudication of feet, legs, arms or hands can be presenting signs that might evolve toward critical limb ischaemia, ulcerations and necrosis. ${ }^{1}$

The pathogenesis of $\mathrm{BD}$ is multifactorial: from the haemostasis point of view, decreased fibrinolysis, ${ }^{2}$ enhanced coagulation activation ${ }^{3}$ and tighter fibrin clots have been reported ${ }^{4}$; from the histology viewpoint there is increased expression of integrins and selectins that favour leucocyte adhesion on the endothelial lining, and from the functional point of view there is reduced flow mediated vasodilatation. $^{5}$

Homocysteine (HC) is a sulphur amino acid, which can be either re-methylated to methionine or trans-sulphurated to cystathionine according to different genes coding for enzymes that control (the) two pathways: a polymorphism in the methylene tetrahydrofolate reductase (MTHFR) C677T gene is associated with decreased enzymatic activities allowing $\mathrm{HC}$ to reach toxic plasma levels that in turn promote thrombosis ${ }^{6}$ and vascular damage. ${ }^{7}$ We performed this

received

July 21,2021

accepted after revision

November 24, 2021

published online

January 20, 2022

Address for correspondence Paul R.J. Ames, MD, MSc, PhD, FRCPath, Department of Haematology, Dumfries Royal Infirmary, Dumfries, United Kingdom (e-mail: paxmes@aol.com).

meta-analysis to evaluate whether plasma $\mathrm{HC}$ has any role in the vascular damage in BD.

We searched MEDLINE and EMBASE according to the Preferred Reporting Items for Systematic Reviews and Meta-Analyses guidelines ${ }^{8}$ from inception to December 2020 using the terms: ['Buerger disease' OR 'thromboangioiitis obliterans'] and [homocysteine' OR 'hyperhomocysteinaemia'] and [methylentetrahydrofolate reductase].

We considered observational, cohort and/or case-control studies reporting the mean/median concentration of plasma HC and the MTHFR polymorphisms in BD patients and in controls from articles published in any language. We excluded case reports, reviews and records with no extractable data. The Newcastle Ottawa Quality Assessment Scale assessed the quality of the studies ${ }^{9}$; random effects meta-analyses for continuous outcomes estimated the standardised mean difference of $\mathrm{HC}$ between groups ${ }^{10}$ and Peto's odds ratio for rare events compared the prevalence of MTHFR TT between groups ${ }^{11}$ (Comprehensive Meta-Analysis, BioStat, Englewood, New Jersey, United States). We could not assess publication bias as funnel plots are invalid with less than 10 articles in the meta-analysis. $^{12}$

The search yielded 36 records that decreased to 29 after duplicate removal; once through with the relevancy screen,

(c) 2022. Thieme. All rights reserved. Georg Thieme Verlag KG,

Rüdigerstraße 14,

70469 Stuttgart, Germany
DOI https://doi.org/ 10.1055/s-0041-1742165. ISSN 0340-6245. 


\section{Plasma homocysteine in Buerger's disease and controls}

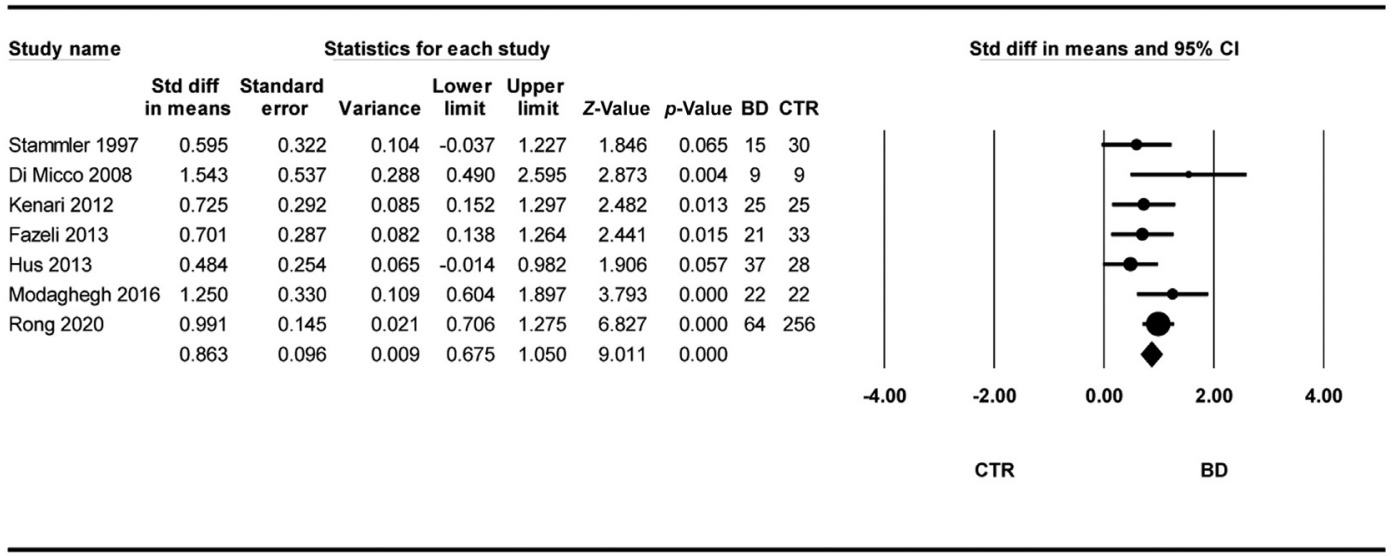

Overall I square $16.8 \%$

A

\section{Plasma homocysteine in Buerger's disease and smoking controls}

\begin{tabular}{|c|c|c|c|c|c|c|c|c|c|}
\hline \multirow{2}{*}{$\underline{\text { Study name }}$} & \multicolumn{7}{|c|}{ Statistics for each study } & \multicolumn{2}{|c|}{ Sample size } \\
\hline & $\begin{array}{l}\text { Std diff } \\
\text { in means }\end{array}$ & $\begin{array}{l}\text { Standard } \\
\text { error }\end{array}$ & Variance & $\begin{array}{c}\text { Lower } \\
\text { limit }\end{array}$ & $\begin{array}{c}\text { Upper } \\
\text { limit }\end{array}$ & Z-Value & $p$-Value & BD & Smokers \\
\hline Stammler 1997 & 0.408 & 0.369 & 0.136 & -0.315 & 1.131 & 1.107 & 0.268 & 15 & 15 \\
\hline Kenari 2012 & 0.695 & 0.291 & 0.085 & 0.124 & 1.266 & 2.386 & 0.017 & 25 & 25 \\
\hline Fazeli 2013 & 0.038 & 0.326 & 0.106 & -0.602 & 0.677 & 0.116 & 0.908 & 21 & 17 \\
\hline & 401 & 0199 & 0.040 & 0.010 & 0.792 & 2012 & 0,04 & & \\
\hline
\end{tabular}

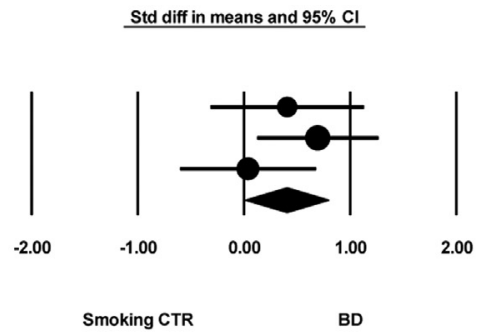

Overall I square $11.4 \%$

B

\section{Methylentetrahydrofolate reductase TT in Buerger's disease}

\begin{tabular}{|c|c|c|c|c|c|c|c|}
\hline \multirow[t]{2}{*}{$\underline{\text { Study name }}$} & \multicolumn{5}{|c|}{ Statistics for each study } & \multicolumn{2}{|c|}{ Events / Total } \\
\hline & $\begin{array}{c}\text { Peto } \\
\text { odds ratio }\end{array}$ & $\begin{array}{l}\text { Lower } \\
\text { limit }\end{array}$ & $\begin{array}{l}\text { Upper } \\
\text { limit }\end{array}$ & $Z$-Value & $p$-Value & BD & CTR \\
\hline awasaki 2000 & 1.543 & 0.517 & 4.612 & 0.777 & 0.437 & $8 / 76$ & $6 / 85$ \\
\hline Brodme & 477 & 0.129 & 1.761 & -1.110 & 0.267 & $2 / 43$ & $9 / 86$ \\
\hline ilueck 2006 & 468 & 0.140 & 1.566 & -1.232 & 0.218 & $7 / 21$ & $11 / 21$ \\
\hline Di Micco 2008 & 11.343 & 1.308 & 98.332 & 2.204 & 0.028 & $4 / 9$ & $0 / 9$ \\
\hline Fu 2019 & 1.544 & 0.840 & 2.839 & 1.398 & 0.162 & $38 / 87$ & $29 / 87$ \\
\hline & 1.193 & 0.547 & 2598 & 0.443 & 0.658 & & \\
\hline
\end{tabular}

Peto odds ratio and $95 \% \mathrm{Cl}$

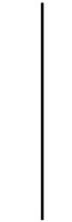

0.01

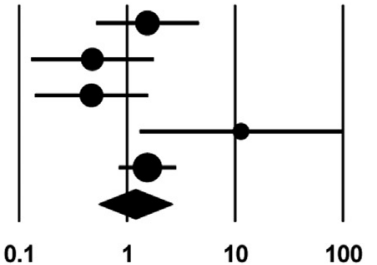

CTR

Overall I square $56.7 \%$

C

Fig. 1 (A) Forest plot of studies investigating plasma homocysteine in Buerger's disease (BD) and controls (CTR). (B) Forest plot of studies investigating plasma homocysteine in Buerger's disease and smoking controls. (C) Forest plot of studies investigating the prevalence of the methylene-tetrahydrofolate reductase TT genotype in Buerger's disease and controls. 
21 records were found eligible but only 7 articles met our inclusion criteria. ${ }^{13-19}$ HC was measured by high-performance liquid chromatography ${ }^{13,15}$ by enzyme-linked immunoassay ${ }^{16,18,19}$ and by fluorescent polarisation immune assay ${ }^{17}$; one study did not report the assay method. ${ }^{14}$ Median and ranges ${ }^{15,17}$ were converted to mean and standard deviation. ${ }^{20}$ Three studies ${ }^{13,15,16}$ had two separate control groups made up of smokers and non-smokers: for the purpose of the meta-analysis, we averaged their $\mathrm{HC}$ concentration as other studies combined together smokers and non-smokers ${ }^{17,19}$ though only one article indicated the number of cigarettes smoked per year by all participants. ${ }^{15}$

The effect size (ES) of plasma HC from $193 \mathrm{BD}$ patients and 428 controls favoured BD ( - Fig. 1A) with low heterogeneity $\left(I^{2}=16.8 \%\right)$ that decreased $\left(I^{2}=11.7 \%\right)$ after exclusion of the study that did not report the method of HC assay. ${ }^{13}$ The ES of plasma HC from 61 BD patients and 57 smoking controls showed a lower heterogeneity $\left(I^{2}=11.4 \%\right)$ but a greatly reduced ES (- Fig. 1B); this implies an effect of smoking on plasma HC in the relevant group. On the other hand, the pooled prevalence of MTHFR TT from 236 BD patients and 288 controls $^{14,21-24}$ was not significantly greater in BD patients than that in control participants (25\% vs. 19\%) (-Fig. 1C) and showed moderate heterogeneity ( $I^{2} 56.7 \%$, $p=0.056)$; removal of the study with the lowest number of participants ${ }^{14}$ changed slightly the prevalence (24.2\% vs. $19.7 \%, p=0.9)$ and the heterogeneity $\left(I^{2} 41 \%, p=0.16\right)$.

Despite the paucity of the available studies, an inherent limitation of our meta-analysis, the resulting data are consistent with an involvement of plasma $\mathrm{HC}$ in $\mathrm{BD}$, but this is unlikely to be genetically driven as we did not find an increased prevalence of the common homozygous MTHFR C677T genotype in the BD populations where this genotype was investigated, whereas other genes of the $\mathrm{HC}$ pathway have not been searched for in BD.

However, the increased oxidative and nitrative stress that accompanies $\mathrm{BD},{ }^{25-27}$ whether or not supported by smoking, ${ }^{28}$ may inhibit cystathionine $\beta$ synthase, ${ }^{29}$ the first enzyme in the trans-sulphuration pathway that catalyses $\mathrm{HC}$ to cystathionine; indeed, this enzyme is susceptible also to disulphide redox inhibition ${ }^{30}$ perpetuating the elevated $\mathrm{HC}$ that via one route maintains a high level of oxidative stress $^{31}$ and via another sustains vascular damage ${ }^{7}$ : in this sense, elevated plasma HC is more an effect of the inflammation that accompanies BD and less likely to be a primary cause of BD. However, attempts to reduce HC seem intuitive: this might be accomplished via the administration of antioxidant agents, which may release cystathionine $\beta$ synthase from its inhibition, rather than by the administration of the $\mathrm{B}$ vitamins that are cofactors in the metabolic pathways of $\mathrm{HC}$.

\section{Funding}

This study is supported by www.fondazioneaps.org, an Italian Registered Charity.

Conflict of Interest

None declared.

\section{References}

1 Choudhury NA, Pietraszek MH, Hachiya T, et al. Plasminogen activators and plasminogen activator inhibitor 1 before and after venous occlusion of the upper limb in thromboangiitis obliterans (Buerger's disease). Thromb Res 1992;66(04):321-329

2 Zheng P, Chen SJ, Shao HZ. Studies on hypercoagulation state in thromboangiitis obliterans. Chin Med J (Engl) 1989;102(01):67-71

3 Qaja E, Muco E, Hashmi MF. Buerger Disease. In: StatPearls [Internet]. Treasure Island, FL: StatPearls Publishing; 2020

4 Undas A, Nowakowski T, Cieśla-Dul M, Sadowski J. Abnormal plasma fibrin clot characteristics are associated with worse clinical outcome in patients with peripheral arterial disease and thromboangiitis obliterans. Atherosclerosis 2011;215(02):481-486

5 Idei N, Nishioka K, Soga J, et al. Vascular function and circulating progenitor cells in thromboangitis obliterans (Buerger's disease) and atherosclerosis obliterans. Hypertension 2011;57(01):70-78

6 Den Heijer M, Lewington S, Clarke R. Homocysteine, MTHFR and risk of venous thrombosis: a meta-analysis of published epidemiological studies. J Thromb Haemost 2005;3(02):292-299

7 Balint B, Jepchumba VK, Guéant JL, Guéant-Rodriguez RM. Mechanisms of homocysteine-induced damage to the endothelial, medial and adventitial layers of the arterial wall. Biochimie 2020;173:100-106

8 Liberati A, Altman DG, Tetzlaff J, et al. The PRISMA statement for reporting systematic reviews and meta-analyses of studies that evaluate health care interventions: explanation and elaboration.J Clin Epidemiol 2009;62(10):e1-e34

9 Wells GA, Shea B, O'Connell D, et al.Ottawa Hospital Research Institute. The Newcastle-Ottawa Scale (NOS) for assessing the quality of nonrandomized studies in meta-analyses. Available at: www.ohri.ca/programs/clinical_epidemiology/oxford.htm

10 Borenstein M, Hedges LV, Higgins JP, Rothstein HR. A basic introduction to fixed-effect and random-effects models for meta-analysis. Res Synth Methods 2010;1(02):97-111

11 Brockhaus AC, Grouven U, Bender R. Performance of the Peto odds ratio compared to the usual odds ratio estimator in the case of rare events. Biom J 2016;58(06):1428-1444

12 Sterne JA, Sutton AJ, Ioannidis JP, et al. Recommendations for examining and interpreting funnel plot asymmetry in metaanalyses of randomised controlled trials. BMJ 2011;343:d4002

13 Stammler F, Diehm C, Hsu E, Stockinger K, Amendt K. The prevalence of hyperhomocysteinemia in thromboangiitis obliterans. Does homocysteine play a role pathogenetically? [in German]. Dtsch Med Wochenschr 1996;121(46):1417-1423

14 Di Micco P, Di Fiore R, Di Micco G, et al. Buerger's disease and hyperhomocysteinemia: is there a relationship? Open Atheroscler Thromb J 2008;1:6-8

15 Kenari AY, Karimi M, Salimi J, Khashayar P. Plasma levels of homocysteine in Buerger's sufferers and healthy heavy smokers and non-smokers. Clin Lab 2013;59(1-2):93-96

16 Fazeli B, Ravari H. Hyperhomocysteinemia as a consequence of life style among patients suffering from thromboangiitis obliterans. Int Angiol 2013;32(04):442-443

17 Hus I, Sokolowska B, Walter-Croneck A, Chrapko M, Nowaczynska A, Dmoszynska A. Assessment of plasma prothrombotic factors in patients with Buerger's disease. Blood Coagul Fibrinolysis 2013; 24(02):133-139

18 Modaghegh MH, Ravari H, Haghighi MZ, Rajabnejad A. Effect of folic acid therapy on homocysteine level in patients with atherosclerosis or Buerger's disease and in healthy individuals: a clinical trial. Electron Physician 2016;8(10):3138-3143

19 Rong D, Lu W, Ge Y, et al. Associations between elevated plasma total homocysteine level and risk of thromboangiitis obliterans in a Chinese population: a matched case-control study. Ann Vasc Surg 2020;62:335-341

20 Hozo SP, Djulbegovic B, Hozo I. Estimating the mean and variance from the median, range, and the size of a sample. BMC Med Res Methodol 2005;5:13 
21 Kawasaki T, Fujimura H, Kakinoki E, Uemichi A, Miyata T. Is there a role for genetic polymorphism of C677T methylenetetrahydrofolate reductase (MTHFR) in Buerger's disease? Thromb Haemost 2000;84(04):736-737

22 Brodmann M, Renner W, Stark G, Seinost G, Pilger E. C 677T methylentetrahydrofolate reductase (MTHFR) polymorphism and thrombangiitis obliterans. Int J Cardiol 2002;83(03):275-276

23 Glueck CJ, Haque M, Winarska M, et al. Stromelysin-1 5A/6A and eNOS T-786C polymorphisms, MTHFR C677T and A1298C mutations, and cigarette-cannabis smoking: a pilot, hypothesis-generating study of gene-environment pathophysiological associations with Buerger's disease. Clin Appl Thromb Hemost 2006;12(04):427-439

24 Fu D, Ding J, Liu J, Ding H, Chen X, Ge X. Association between single nucleotide polymorphisms of the MTHFR gene and thromboangiitis obliterans. Int J Clin Exp Med 2019;12:12531-12537

25 Sharebiani H, Fazeli B, Maniscalco R, Ligi D, Mannello F. The imbalance among oxidative biomarkers and antioxidant defense systems in thromboangiitis obliterans (Winiwarter-Buerger Disease). J Clin Med 2020;9(04):1036
26 Aliee A, Zahedi Avval F, Taheri H, et al. The status of nitric oxide and its backup, heme oxygenase 1 , in thromboangiitis obliterans. Rep Biochem Mol Biol 2018;6(02):197-202

27 Arslan C, Altan H, Beşirli K, Aydemir B, Kiziler AR, Denli S. The role of oxidative stress and antioxidant defenses in Buerger disease and atherosclerotic peripheral arterial occlusive disease. Ann Vasc Surg 2010;24(04):455-460

28 van der Plas A, Pouly S, de La Bourdonnaye G, Baker G, Lüdicke F. Influence of smoking on levels of urinary 8-iso Prostaglandin F2 $\alpha$. Toxicol Rep 2018;6:18-25

29 Wang H, Sun Q Zhou Y, et al. Nitration-mediated deficiency of cystathionine $\beta$-synthase activity accelerates the progression of hyperhomocysteinemia. Free Radic Biol Med 2017;113:519-529

30 Niu W, Wang J, Qian J, et al. Allosteric control of human cystathionine $\beta$-synthase activity by a redox active disulfide bond. J Biol Chem 2018;293(07):2523-2533

31 Voutilainen S, Morrow JD, Roberts LJ II, et al. Enhanced in vivo lipid peroxidation at elevated plasma total homocysteine levels. Arterioscler Thromb Vasc Biol 1999;19(05):1263-1266 